\title{
LA PRÁCTICA CULTURAL DEL BORDADO \\ DE SAN ANTONINO EN OAXACA - MÉXICO
}

Esmeralda Castañeda de la Cueva*

DOI: 10.33571/revistaluciernaga.v10n20a2

\section{Resumen}

Desde niña he tenido interés por las actividades culturales en Oaxaca, el cual nació de observar el entusiasmo de mi madre y mi abuela por bailar sones, preparar delicias gastronómicas o asistir a misas de gallo. Aprendí de sus pies y manos. Viendo a través de sus ojos y sus memorias, fui creando mi concepción de Oaxaca y sus actividades artísticas, culturales y religiosas acercándome a conocer sus tradiciones y costumbres. Naci y crecí en su capital, los Valles Centrales, lugar en el que se creó la blusa y el vestido conocido como "de San Antonino", prenda que se elabora de manera individual, familiar y colectiva. A partir de un proceso artesanal y de compartición de saberes, se tejen los hilos que construyen los dibujos de las flores en su diversidad de colores y que reflejan las experiencias vividas y transmitidas de la comunidad.

En este artículo me aboco a desentrañar esta práctica cultural de este bordado, por medio del cual las mujeres de esta región dan cuenta de sus sentires, saberes, cotidianidad e identidad.

Palabras clave: bordado, práctica cultural, comunidad, vida cotidiana, memoria, identidad.

Recibido. Junio 25, 2018

Aceptado. Julio 23, 2018

*Maestranda en Comunicación y Cambio Social de Universidad Iberoamericana Puebla, México. Orcid. https://orcid.org/0000-0003-1793-1269, email: esmeralda.ccueva@gmail.com 


\title{
THE CULTURAL PRACTICE OF THE SAN ANTONINO
}

\section{EMBROIDERY IN OAXACA - MEXICO}

\author{
Esmeralda Castañeda de la Cueva
}

DOI: 10.33571/revistaluciernaga.v10n20a2

\section{Summary}

Since childhood I have been interested in cultural activities in Oaxaca, born of observing the enthusiasm of my mother and grandmother for dancing sones, preparing gastronomic delights or attending midnight masses. I learned from their feet and hands. Seeing through their eyes and their memories, I was creating my conception of Oaxaca and its artistic, cultural and religious activities, getting closer to knowing its traditions and customs. I was born and raised in the capital city, in the Central Valleys region, where the blouse and dress known as "de San Antonino" was created. This is a garment that is made individually, familiarly and collectively. From a process of craftsmanship and sharing of knowledge, the threads that construct the drawings of flowers in their diversity of colors are woven and reflect the lived and transmitted experiences of the community.

In this article I unravel the cultural practice of this embroidery, through which the women of this region give an account of their feelings, knowledges, daily life and identity.

Keywords: embroidery, cultural practice, community, everyday life, memory, identity 


\section{LA PRÁCTICA CULTURAL DO BORDADO \\ DE SAN ANTONINO EM OAXACA - MEXICO}

\section{Esmeralda Castañeda de la Cueva}

DOI: 10.33571/revistaluciernaga.v10n20a2

\section{Resumo}

Desde o início, ele participa das atividades culturais em Oaxaca, na cidade de observar o entusiasmo de mi madre e mi abuela por bailar sones, preparar delicias gastronómicas o asistir a misas de gallo. Aprendiz de sus pies y manos. Viendo a través de sus ojos y sus memorias, fui creando mi concepción de Oaxaca y sus actividades artísticas, culturais e religiosas acercándome a conocer sus tradiciones y costumbres. Nací e crecí su su capital, os Valles Centrales, lugar no qual foi criado a blusa e o vestido conocido como "de San Antonino", que é uma pessoa de família, familiar e coletiva. A partir de um processo artesanal e de compartimentação de saberes, os títulos que constroem os dibujos das flores em sua diversidade de colores e que reflejan as experiências vividas e transmitidas da comunidade.

En este artículo abotoado a desentrañar esta práctica cultural de este bordado, por medio del cual las mujeres de esta región e cuenta de su sentires, saberes, cotidianidad e identidad.

Palavras-chave: bordado, prática cultural, comunidade, vida cotidiana, memória, identidade. 


\section{Introducción}

Oaxaca es un Estado al sur de México. Cuenta con 570 municipios divididos en regiones: la Costa, el Papaloapan, la Sierra Norte, la Sierra Sur, el Istmo, la Cañada, la Mixteca y los Valles Centrales (1). Cada región preserva su cultura e identidad en múltiples formas.

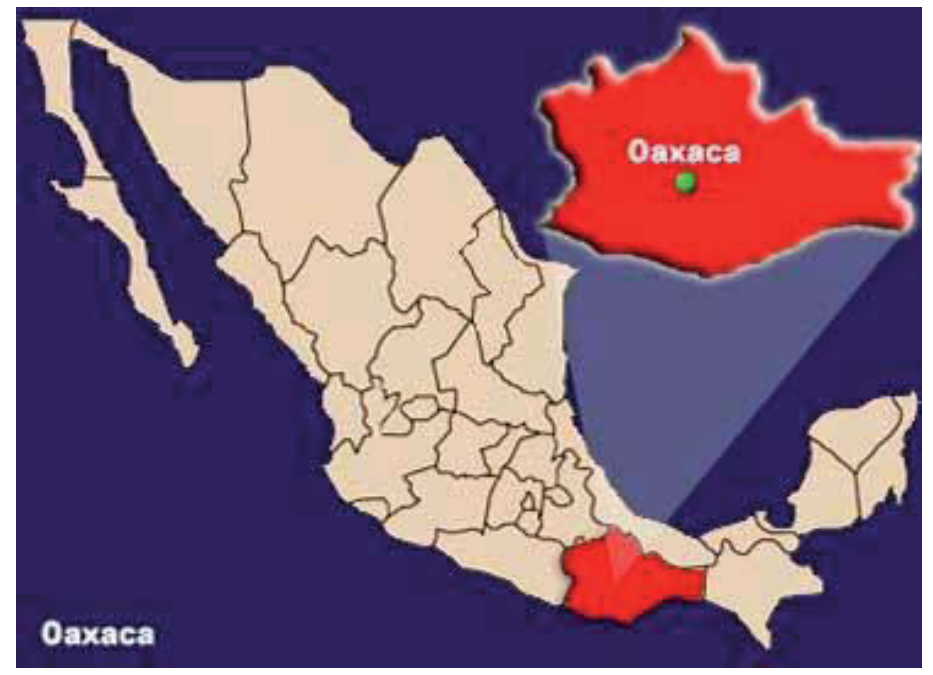

Tomado de: https://finanzasoaxaca.gob.mx/pdf/inversion_publica/pmds/1 1_13/103.pdf

San Antonino Castillo Velasco es un municipio del distrito de Ocotlán de Morelos. Es una comunidad pequeña que alberga cerca de 6 mil habitantes. Dentro de sus actividades principales resaltan el cultivo de rosas en los campos, el trabajo con carrizo y la creación de artesanías (2). Su cercanía con la capital hace que tenga carreteras, caminos, infraestructura, telecomunicaciones, incluso una línea invisible de comercio llamada "Ruta mágica de las artesanías" (3).
El bordado sobre el que centré $\mathrm{mi}$ atención para esta investigación se conoce como "de San Antonino", lleva el mismo nombre de la comunidad, sin embargo, también realizan esta actividad en la capital del Estado y en otros municipios de la región de Valles Centrales. Para la elección de las mujeres a las que entrevisté y de los colectivos en los que realicé la observación participante el criterio principal fue que realizaran el bordado "de San Antonino".

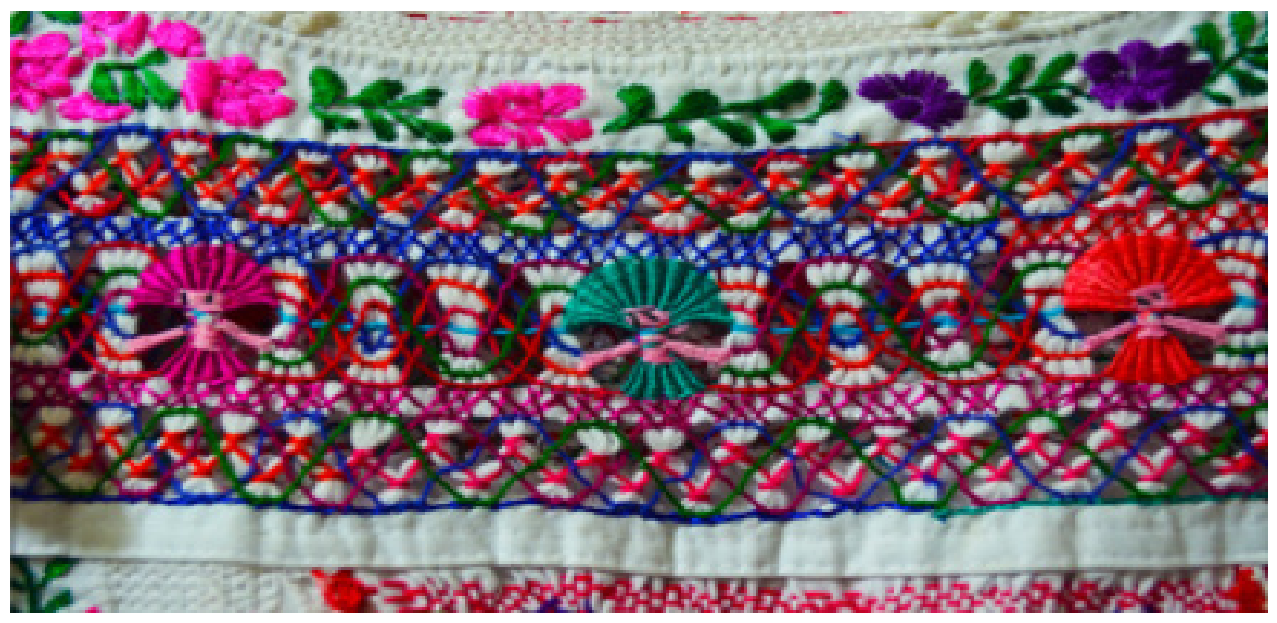




\section{Metodología}

En la obtención de los datos que dan sustento a la investigación utilicé una metodología cualitativa, orientada al estudio de los significados de las acciones humanas y de la vida social, con técnicas de tipo etnográfico que me acercaron a quienes se dedican al bordado en la ciudad de Oaxaca y en San Antonino Castillo Velasco. Tomé elementos de la etnografía (4) para acercarme a la realidad $e$ interpretarla tomando en cuenta las acciones, ideas e interpretaciones que las mujeres tienen en relación con la práctica del bordado.

Utilizando observación participante (5), entrevistas y pláticas informales pude crear un lazo con diversos colectivos, familias y vendedoras. El primer acercamiento en campo me sirvió para observar el transcurrir de los días en la comunidad de San Antonino y las formas de trabajo de quienes vendían prendas bordadas sobre el andador turístico en la ciudad de Oaxaca (6). Las pláticas informales sucedieron una vez que mis visitas eran constantes. Estas se orientaron hacia temas como la comunidad, la identidad y la vida cotidiana, incluyendo chismes del día, las malas ventas que hubo, los pleitos entre colectivos, las fiestas de julio (7) o los hijos y su educación, entre otros. Las conversaciones me revelaron lo que para cada mujer era importante y lo que en su conjunto construía las historias de las mujeres que participaban en la práctica del bordado.

Realicé entrevistas de relatos de vida, enfocándome en la práctica del bordado como aspecto central de las conversaciones con las mujeres, esta técnica me permitió acercarme y conocerlas a nivel personal. A partir de las entrevistas obtuve cuatro relatos de vida, el acercamiento con cinco colectivos en San Antonino, la profundización en la creación, organización y venta del bordado, así como la jerarquización de roles de trabajo de un colectivo en particular llamado Aguja de Plata.

Realicé registro y un diario de campo (8) con las actividades de investigación. En la ciudad de Oaxaca, recorrí la zona del centro donde está la mayor concentración de venta de artesanías. Visité los corredores artesanales observando los distintos puestos de trabajo y conversando con las artesanas sobre la práctica del bordado en sus comunidades encontrando diferencias de trabajo y organización, así como realidades distintas en su cotidianidad. En estos corredores conocí a Beatriz, Juana y Mari, pertenecientes a distintos municipios de Oaxaca (9), así como a Marta perteneciente al colectivo Aguja de Plata ubicado en San Antonino Castillo Velasco.

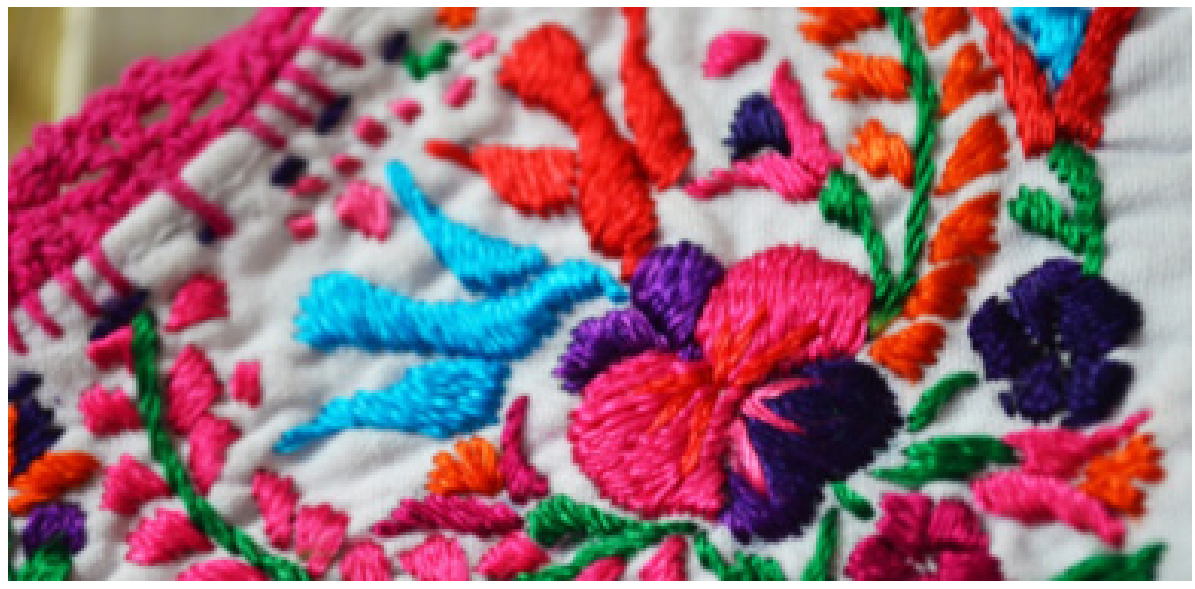

Fuente: Foto propia. 


\section{Los encantos y desencantos de los hilos: Beatriz, Juana, Mari y Marta}

Beatriz es de Pinotepa Nacional (10), su esposo es de San Pedro Mártir (11), ella aprendió de sus suegros y cuñadas la práctica del bordado "de San Antonino". Ella junto con la familia de su marido han creado prendas tradicionales (12), pero también realizan patrones más ceñidos, vestidos más sueltos, formas menos rigurosas y usan colores más "combinables", debido a la demanda de compradores que buscan colores serios o no tan chillantes. Con su marido decidió vender en el andador turístico durante el mes de julio en la ciudad de Oaxaca. A Beatriz la conocí caminando, vendiendo en una esquina preocupada por recuperar a través de la venta, un poco del tiempo invertido en la creación de sus piezas.

Juana es de San José del Progreso (13) vende sus blusas en la ciudad de Oaxaca en un puesto ubicado en una feria de artesanías con motivo de las fiestas de julio. Ella ha vivido en distintos lugares dentro y fuera de México para subsistir. Por ejemplo, vivió en Mexicali en la frontera norte trabajando en quehaceres domésticos. lba y venía de Oaxaca llevando blusas con el bordado "de San Antonino", sin embargo, le regateaban, minimizaban su trabajo y esfuerzo así que decidió no llevarlas más. Juana borda por gusto, porque se lo enseñaron de niña, pero sabe que a veces el trabajo no sale, se mal paga y debe buscar otra forma de llevar dinero a su casa. Ella dice:

"Mis ojos se han quedado en esto, pero no importa porque me gusta hacerlo, lo hago con gusto, cuando se puede me va bien y cuando no, hay que buscarle".

Mari es de San Antonino, pero vive en la ciudad de Oaxaca desde hace varios años. Mari borda desde niña, al igual que a sus hermanas, le enseñó su mamá. Bordar era una actividad para sentarse juntas y en silencio a trabajar. Mari se enamoró y sus padres no lo aceptaron. Con regaños, gritos y hasta golpes evitaron que se fuera, hasta que se salió de su casa. Ahora ella tiene dos hijas de las cuales está orgullosa pues asisten a la universidad, una de ellas está dedicada por completo al estudio y la otra conjunta la universidad con la actividad que realiza su mamá, el bordado.

Marta es una maestra jubilada, se dedicó 30 años a la docencia recorriendo varios municipios de Oaxaca. Regresó a San Antonino antes de jubilarse y se quedó dando clases en la primaria de la comunidad. Durante dos años, fue regidora de educación en San Antonino y formó parte del cabildo.

Ella se encarga de coordinar el colectivo Aguja de Plata, me contó que este se creó por una élite artesanal que acaparaba el trabajo y explotaba a sus compañeras bordadoras con alta producción y bajos pagos. Marta busca a través de la práctica del bordado establecer un vínculo con jóvenes de la comunidad para que se acerquen y conozcan las historias de sus tradiciones y trabajos, y vean cómo el bordado se basa en la cooperación de las mujeres que recuperan las experiencias individuales para formar una blusa, al mismo tiempo que forman una identidad del pueblo.

En San Antonino hay cinco colectivos dedicados al bordado, estos son: 1) Hazme si puedes, 2) Manos mágicas, 3) Rosa de Castilla, 4) Flores y pensamientos y 5) Aguja de Plata. En mis visitas a San Antonino trabajé con este último.

El colectivo Aguja de Plata se inicia bajo la coordinación de Marta con el apoyo 
del sacerdote del pueblo, el padre Hilarino (14). Ellos visitaron a mujeres conocidas que pudieran estar interesadas por el proyecto y se juntaron 25 mujeres para comenzar el colectivo. Hoy en día el espacio en donde se reúnen es un cuarto de la casa de Marta, parte del trabajo que ella realiza es buscar talleres que les permitan a las mujeres tener ingresos diversos, aprender otras disciplinas como pintura en tela, repostería, estilismo, incluso medicina tradicional, que es la actividad que les ha permitido seguir sosteniendo el colectivo cuando las ventas están bajas. Dentro del colectivo conocí a la "güerita" quién se encarga de pegar las piezas y formar la blusa, también a Arely que se dedica a llevar el control de gastos del colectivo y además es una de las hijas de Marta.

Las mujeres y colectivos dedicados al bordado "de San Antonino" usan más de 20 colores de hilos para dar vida a las flores que se bordan en la blusa o el vestido. Son los colores de la naturaleza que rodea las comunidades a las que pertenecen. Estas mujeres tienen en común el arte de bordar y deshilar y a través de este una memoria llena de recuerdos y vivencias. A pesar de ser tan diferentes, al bordar se transmiten experiencias y cruzan historias generando un diálogo entre ellas y perpetuándolo en las flores de las prendas.

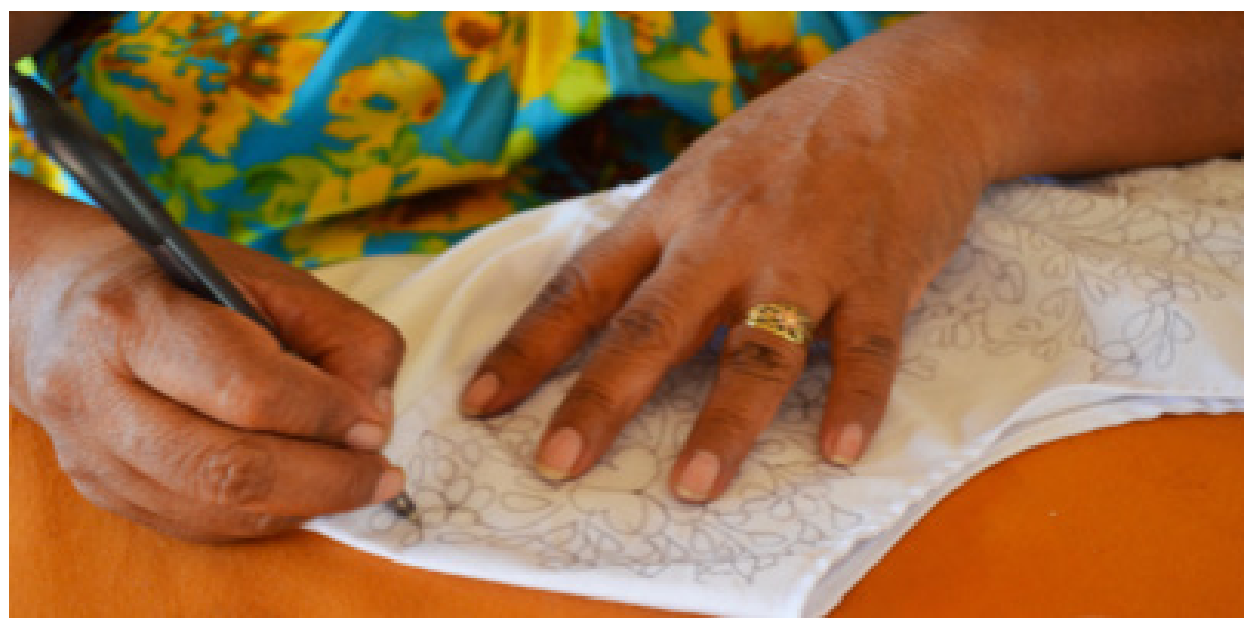

Fuente: Foto propia.

\subsection{Bordando la vida}

"El arte textil es una práctica milenaria heredada y actualizada por muchos pueblos originarios de América Latina. Este hace parte de su identidad y estética cultural" (Gil, $59,2016)$.

La creación de textiles es una actividad que se aprende intergeneracionalmente. En Oaxaca, las diversas artesanías se crean desde la familia. Las que son artesanas, que incluyen a las bordadoras, han ido transmitiendo conocimientos y aportando desde sus experiencias las transformaciones que la artesanía ha tenido con el paso de los años. Para las familias de Valles Centrales bordar es una actividad destinada a las mujeres del hogar con la intención de enseñar un oficio, unión familiar o establecer una disciplina.

En mis visitas a San Antonino pude observar como esta práctica ha sido enseñada por las mujeres mayores a sus hijas y nietas, continuando un camino de reconocimiento familiar y social a través del bordado. La práctica del bordado identifica y valora aportes estéticos y artísticos a partir de la relación con la 
naturaleza, con el contexto social y político. Es un entramado de relaciones en conexión directa con las prácticas cotidianas propias de los pueblos (Gil, 2016). Por ejemplo, para los tejedores Ikoots de San Mateo del Mar (15) en Oaxaca, la práctica del bordado representa un proceso de transformación. sobrevivencia y realización personal a través de su trabajo y creatividad; relacionan la cultura y tradiciones de la comunidad con su proceso de formación a lo largo de su vida personal, en las experiencias, las relaciones familiares, sociales y culturales, así como la interacción y socialización con los demás. La práctica del tejido constituye un elemento en la formación como sujetos basados en la forma de vida comunitaria que entrecruzan conocimientos culturales (Carvente y Hernández, 2017).

La práctica del bordado ha funcionado como una doctrina para las mujeres al enseñarles uno de los quehaceres domésticos; también como forma de resistencia y lucha por los derechos humanos; algunos grupos de mujeres han creado colectivos para hacer denuncias en contextos políticos, así como para buscar la dignificación de la historia, del ser indígena en un mundo global, y de las mujeres por medio del valor artístico y de la propia identidad cultural. Bordar es un trabajo que libera y funciona como resistencia. El bordado permite conocer saberes y cosmologías de un pueblo haciendo que esta práctica artesanal se actualice con y en el tiempo (Blanca, 2014).

Durante las conversaciones que sostuve y las que presencié descubrí cómo con el bordado se recuperan las historias de las abuelas.

En los espacios en los que se reúnen las mujeres, aparecen relatos de sus vidas, hechos políticos, sociales y cotidianos. Ellas hablan del paso de la radio a la televisión, los conflictos socio-políticos y magisteriales en Oaxaca, la lucha por el territorio de los pueblos indígenas, las vastas mayordomías (16), las fiestas patronales, los bailes representativos de cada región, la historia de la gastronomía, las visitas al molino, los días de plaza (17) y baratillo (18), dar a luz un hijo, perder a un familiar cercano, la celebración del día de muertos, la sexualidad y el cuerpo.

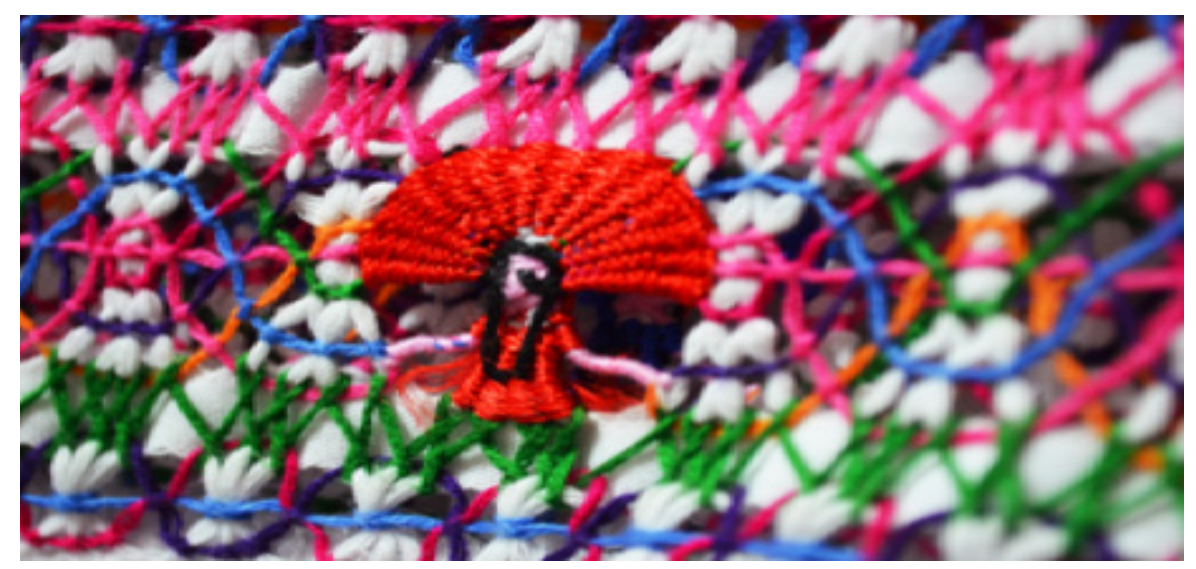

Fuente: Foto propia

Para las mujeres del Colectivo Aguja de Plata, la práctica del bordado transmite mucho más que los conocimientos para la creación de la artesanía y la organización de un sector de la población. El comer juntas, aprender nuevas técnicas y habilidades, estar constantemente en capacitación, generar ingresos a través de diversos oficios, realizar las actividades en conjunto y por el bienestar de cada una de las mujeres, hace que el espacio de trabajo genere una dinámica de convivencia que produce empatía y motivación para participar. 
Doña Mari, una integrante del colectivo que se encarga de pegar las piezas decía, "el ambiente para trabajar y la confianza, hacen que una quiera venir con gusto, porque todas nos echamos la mano y todas sabemos en qué somos buenas y cómo sacamos adelante al colectivo desde nuestro trabajo individual".

\subsection{Deshilando historias. Experiencias cotidianas}

García (1989) expresa que los oficios, la creación de artesanías, las actividades domésticas, recreativas, religiosas y cualquier proceso de producción o reproducción social son prácticas culturales que las sociedades llevan a cabo y de las cuales se van aprendiendo nuevas formas en el desarrollo de su día. Giménez (2009) y Thompson (1998), llaman "formas culturales" a los artefactos - comportamientos cargados de significados como las obras de arte, ritos, danzas que se interiorizan en lo cotidiano y producen experiencias comunes y compartidas en distintos territorios, las cuales se diferencian a través de las pertenencias sociales y rasgos particulares que construyen una identidad.

Las prácticas culturales son el rehacer diario de las actividades cotidianas con cargas de significados a partir de experiencias, sentimientos y emociones del pasado y de la actualidad. Se producen a partir de un territorio, la historia de una comunidad y la religiosidad que profesan. Roberto Blancarte (2010) desarrolla estos temas de la siguiente forma: 1) el territorio, delimita las características económicas y políticas de un entorno; 2) la historia, es un eje central en donde se exponen los acontecimientos que han constituido las distintas etapas de una sociedad; y 3) la religiosidad, figura como un indicador de identidad creando dinámicas de pertenencia.

En el caso de esta etnografía, el territorio está situado en la Ciudad de Oaxaca y
San Antonino Castillo Velasco, sus características se asemejan en el tipo de terreno, actividades económicas, sistemas políticos y prácticas culturales. La historia enmarca a la región con sus variaciones en cada municipio y la evolución social que se ha tenido con el paso del tiempo. Para las familias bordadoras la historia viene de sus bisabuelas y abuelas, experiencias que se transmiten en la oralidad y que se conservan a través de la vestimenta que crean. El territorio y la historia se vuelven puntos de partida para aquellas mujeres que hoy realizan la práctica del bordado pues llevan en el proceso de su creación las memorias de quienes fueron precursores de una actividad económica, social y manual, que permite además crear un lazo con quienes saben de esta técnica. La religiosidad transmite la cultura de la comunidad y la ofrenda, pues las flores se usan para la iglesia y adornar los santos. Las flores evocan la vida y la muerte, los elementos naturales, los colores y las formas.

En el Colectivo Aguja de Plata las actividades se cruzan, por ejemplo una prenda, pasa por las manos de 5 o 10 mujeres, cada una armar cada pieza según la técnica a la que se dedican y se van intercambiando para complementarla. Se generan nuevos códigos en los colores, las formas de los dibujos y la fuerza del bordado teniendo como referencia el territorio que han habitado, el espacio de trabajo que comparten, las historias de vidas que se tejen y las nuevas historias que surgen en ese convivir diario. 
Hay mujeres mayores que prefieren el "bordado tradicional" mantienen las guías de flores, sus tonos rosas, rojos y naranjas, tal como se ve el jardín cuando se visita el campo de rosas de castilla. El complemento a este "bordado tradicional" será un corte menos holgado que va a ceñirse a la cintura y estiliza la figura de quien usará la prenda, alguien más deshilará zancudos, nacionales o muñecos (19).

El deshilado en las prendas permite realizar varias figuras en la blusa o vestido, ejemplos de ello son los muñecos que son figuras humanas diminutas, los zancudos que forman una cruz al centro y el nacional que permite observar una guía de flores.

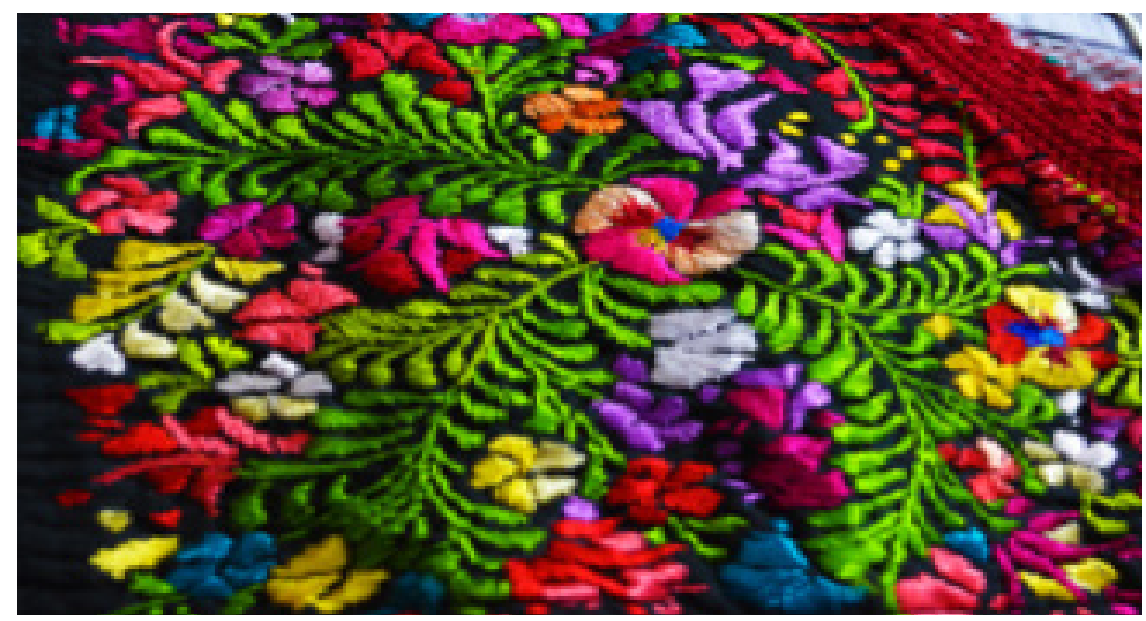

Fuente: Foto propia

Las mujeres redescubren en el bordado, las historias de otras mujeres. La técnica que heredaron y aprendieron en lo individual, fortalece su relación con el pasado familiar y adquiere un significado común cuando lo comparten con las compañeras del colectivo cohesionándose las nuevas realidades percibidas. Cada una de estas mujeres pertenece a distintos municipios de Oaxaca lo que hace que su contexto varíe en la elaboración de las prendas pues su significado será influenciado por sus referentes pasados.

Por ejemplo, Beatriz conserva los colores vibrantes de su región, utilizándolos en el bordado de Valles Centrales. Juana dice que el bordado es familiar, es compartido y conjuga las emociones y expresiones de quienes lo realizan, sin embargo, en cada comunidad se borda distinto. Marta recupera los conocimientos de su madre y abuela y los comparte con mujeres de la comunidad para que no se pierda la técnica, ella borda tradicionalmente.

La práctica del bordado se complementa con las actividades heredadas pues se apoyan de nuevas percepciones, de los problemas o la solución de conflictos para mejorar una técnica que fácilmente se ve influenciada por el exterior. Beatriz debe llevar y recoger a sus hijos a la escuela, Juana debe continuar sus empleos en labores de casa, Marta asistir al mercado para comprar las cosas del almuerzo, Arely repasar los pasos de baile con su hija, la "güerita" lavar la ropa que juntó en la semana y Mari seguir en sus clases de repostería. Las mujeres buscan trascender plasmando en las flores travesías de vida y aportando sus diseños, su elección de colores, su pedazo de historia en la comunidad y la convivencia familiar y social. 
La cultura, según Giménez (2016), se puede definir como el proceso de continua producción, actualización y transformación de modelos simbólicos a través de la práctica individual y colectiva, en contextos históricamente específicos y socialmente estructurados, presente en el mundo del trabajo, tiempo libre, vida familiar, jerarquías sociales y relaciones interpersonales que componen una colectividad. La cultura es una clave necesaria para descifrar la dinámica social para la comprensión de los comportamientos y prácticas sociales que forman la memoria y la cohesión de los actores de un colectivo legitimando o deslegitimando sus acciones. Las experiencias y sentimientos son parte de estas prácticas que refieren también los valores de una tradición, pasa por las experiencias sociales y "los mundos de vida" de los actores en interacción.

Giménez (2016) refiere que a los procesos de actualización de modelos simbólicos en las prácticas individuales y colectivas así como en las del bordado, a partir de la técnica heredada que se adecua a nuevos métodos de producción.

En el caso de Mari y sus hermanas la práctica del bordado se aprendió como una actividad familiar y con el tiempo se ocuparon nuevos métodos en el diseño de una prenda. Durante su creación las memorias de su pasado se hacen presentes, cuando el tejido queda aguado es porque las mujeres se están distrayendo en resolver problemas y a veces queda muy fruncido porque estaban de malas y jalaron de más los hilos. Mari me comentó que a veces llora cuando borda porque recuerda el momento que se fue de casa, a veces se le corta el hilo cuando piensa en la relación que tuvo con sus padres.

Ella dice que cuando el bordado le queda finito es porque está en paz. Estas emociones se adecuan con nuevos procesos en la producción del vestido o blusa pues utilizan patrones "de moda" para tener un mayor impacto en su venta y ahora se busca interactuar con lo moderno para fusionar el conocimiento heredado y sus cargas emotivas con la costura, la comercialización y la transmisión de una técnica de bordar que se ha vuelto evolutiva.

En el acercamiento con el bordado pude percibir las emociones que las mujeres compartían en su proceso de trabajo, desde sentirse cómodas por el bienestar familiar hasta sentir la impotencia de problemas que parecían no poder resolverse. El bordado a su vez es canalizador de las emociones de las tejedoras.

En "Aguja de Plata" observé que las mujeres no solo se sientan a bordar, mientras lo hacen otras están planchando, cosen, hacen la comida, le dan de comer a los animales, reciben gente, escuchan música, organizan fiestas, cantan, hablan de enfermedades, murmuran rezos, aprenden inglés, barren, se ríen de algunos chistes, se miran a los ojos y asienten con la cabeza, se guardan secretos, algunos días lloran, comen juntas, hablan de sus hijos, etc. Hubo días en que las vi alegres, bordaban derechito, sin nudos y con los colores más alegres; también noté a mujeres silenciosas, serias y su bordado fue sobrio; los colores de sus bordados se encimaban y se volvían una mancha de un solo tono que a lo lejos parecía un nudo de hilos sin fin.

Las mujeres bordan en buenos y malos días, con la esperanza de que mientras lo hacen se vayan disipando o aumentando alegrías o angustias y el resultado final es una obra artesanal única en su tipo cargada de emociones que no serán posibles conocerse, aunque quizás la tonalidad de sus colores las revelen. 
La convivencia me acercó a sus emociones y entre charlas diarias a su pensamiento y sentimientos; $\mathrm{mi}$ primer argumento lo obtuve solo de observarlas, ellas después asumieron que así era, los días buenos hacen bordados coloridos, simétricos y extraordinarios, los días malos hacen bordados seductores y misteriosos resaltándose por sus colores contrastantes.

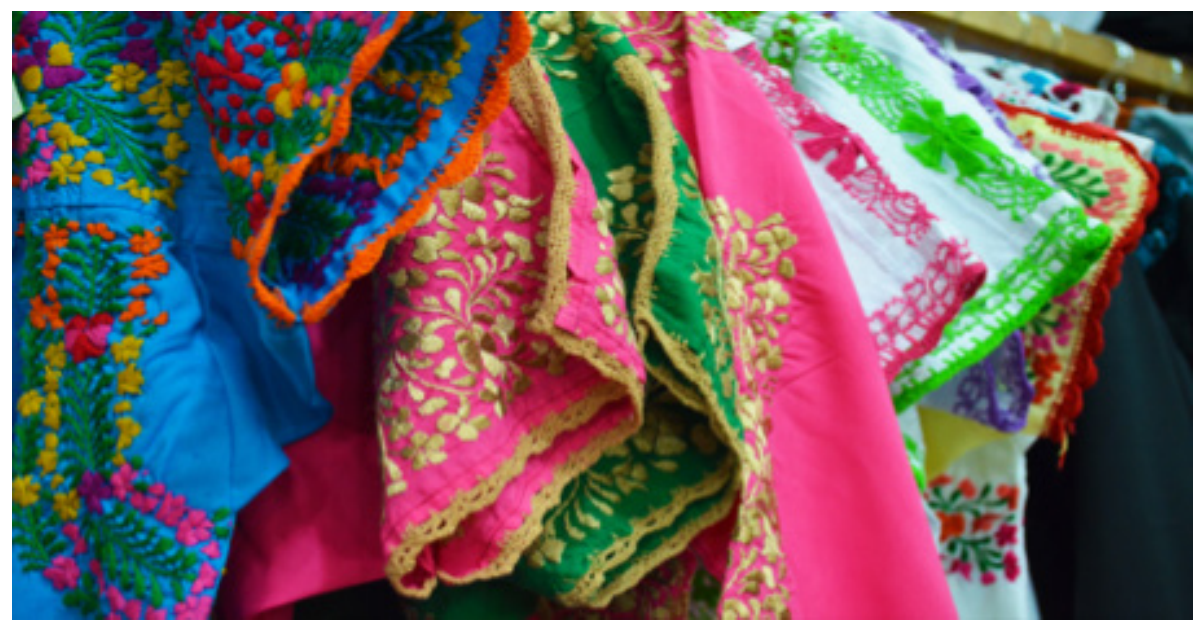

Fuente: Foto propia.

\subsection{Tejiendo comunidad}

Almeida y Sánchez (2014) hablan de comunidad y de sociedad como construcciones teóricas que evolucionan en el tiempo, que expresan diversas formas de organización y convivencia, así como el afecto y la emotividad social que mantiene unidos a sus miembros. La comunidad desde esta perspectiva existe cuando la acción es recíproca a un sentimiento de pertenencia, busca integrar sus relaciones, determina la colaboración y el intercambio para tomar decisiones a partir de las costumbres, el habitar social y la relación con la naturaleza.

En esta idea de organización y convivencia, el bordado "de San Antonino" conlleva un proceso de varias manos para su creación, lo cual lo vuelve único, lleno de momentos personales de cada mujer que bordó su parte. Por ejemplo, Marta al bordar resignifica un conocimiento que forma parte de la comunidad, sus nietas lo reciben como una herencia familiar; en el caso de Beatriz, bordar le permite crear un vínculo con su marido y con la familia de este; a
Mari esta labor le remite al lugar en que nació y creció. La colaboración de cada mujer en el bordado vincula las memorias y lo carga de emociones, sentimientos, pasiones y sueños.

La creación de la prenda, como indiqué anteriormente, implica organización y trabajo conjunto. Las mujeres con el paso del tiempo han desarrollado equipos de trabajo para facilitar la producción, pero también han reafirmado sus conocimientos con habilidades que les permiten la rapidez y la autenticidad para el dibujo, bordado, deshilado, cosido y pegado de las piezas. El hecho de formar equipos refiere a una organización en el trabajo de cada familia, grupo $\mathrm{O}$ colectivo y refleja los conocimientos y experiencias vividas de cada persona. No obstante, hay algunas mujeres que han adoptado la industrialización y la seriación de los materiales de trabajo para realizarlo con más rapidez. Por ejemplo, Marta me contó acerca de Severa, una bordadora que trabaja para el colectivo "Hazme si puedes" y que también trabaja en lo individual para 
tener ingresos más altos. Ella mandó a imprimir los dibujos sobre las blusas haciendo una serie de la misma guía de flores y causando el desagrado de Marta al saber de esta falta de "tequio" (20) con las otras mujeres.

Las formas comunitarias establecen y organizan relaciones de "compartencia" (Martínez, 2016), creando vínculos que generan equilibrios dinámicos no exentos de tensión que puede ocasionarse en la reproducción de la vida social (Gutiérrez y Salazar, 2015). Estos equilibrios se generan al ocupar un mismo territorio en el cual se desarrollan actividades cotidianas que van volviéndose prácticas.

Para Gilberto Giménez (2016) el territorio constituye un espacio de inscripción de la cultura. Funge como un área de distribución de instituciones y prácticas culturales. El territorio puede ser apropiado subjetivamente como objeto de representación y de apego afectivo y sobre todo como símbolo de pertenencia socio-territorial. Giménez (2009), Pollini (1990) mencionan que las pertenencias sociales implican la inclusión en una colectividad hacia la cual experimentan un sentimiento de lealtad, implica compartir el complejo simbólico-cultural que la define. Las personas se convierten en miembros de esta colectividad y adquieren una conciencia de una común pertenencia. Estos elementos pueden ser el credo, los dogmas, los valores ético-religiosos inculcados a través de un vasto sistema ritual. En las diversas comunidades de los Valles Centrales, la práctica del bordado ocasiona una convivencia en el espacio habitual y de trabajo creando una interacción entre sus actores.

Hobsbawn (en Bauman, 2003) dice que los hombres y mujeres buscan grupos a los que puedan pertenecer en un mundo en el que todo lo demás está cambiando y nada es seguro. Para Young cuando la comunidad se colapsa la identidad se inventa y se mantiene como un refugio de seguridad y confianza. La paradoja es que para ofrecer esta seguridad la identidad niega su origen, "tiene que recurrir a conjurar un fantasma de la misma comunidad que florece gracias a la promesa de resurrección de los muertos" (Bauman, 2003), en otras palabras, la recuperación de la memoria. Esta permitirá evocar las historias de vida personales, colectivas, familiares o de la comunidad recuperando procesos y técnicas del bordado.

\subsection{Memorias y vida cotidiana}

La memoria colectiva es el conjunto de representaciones producidas por miembros de un grupo. En Giménez (2009), según Candau (1998) una memoria fuerte es generadora de identidades igual de fuertes, coherentes, compacta y profunda para los grupos. Santagada (2003) afirma que las identidades socioculturales están a merced del esfuerzo de crear referentes comunes en el imaginario de las poblaciones disgregadas ratificadas como historias y augurando un porvenir renovando o fortaleciendo vínculos sociales. La identidad se construye a partir de la memoria, los actores de una comunidad recuperan en lo individual, las expresiones y experiencias que han vivido a lo largo de su vida, permite valorar como se ha formado un grupo, una familia, un colectivo, una comunidad o una sociedad.

La articulación de la memoria de los miembros de un grupo genera una memoria colectiva que será el conjunto de representaciones producidas por cada uno de estos miembros y que además nos remite a la pertenencia a un sitio. La memoria colectiva se aprende y necesita ser reactivada continuamente mediante procesos generacionales de socialización que es lo que se llama "tradición", es decir, el proceso de comunicación de una memoria de generación en generación (Giménez, 2009). 
La práctica del bordado permite la recuperación de la memoria para la construcción de las identidades de las mujeres que participan de ella. Para ellas, el bordado siempre fue una actividad en sus vidas: como adhesivo, para juntar a las mujeres de la familia y enseñarles una actividad con la que podrían realizar prendas y detalles para el hogar, poder casarse y ser mujeres "ejemplares". Tal es el caso de Mari, quien aprendió esta actividad de su madre, esperando que un día pudiera casarse y continuar enseñándole a sus hijas; como una actividad económica para solventar familias, pues al vender las prendas ayuda a que llegue comida a la mesa; como causante de dolor para aquellas mujeres que querían estudiar y no les era permitido o aquellas que estudiaban, pero debían hacer las actividades cotidianas primero. Las hijas de Marta dejaron de lado la práctica porque era difícil realizar una venta y sobretodo porque querían estudiar y hacer una carrera.

Es a partir de lo cotidiano que se dan los encuentros y desencuentros. Mediante la oralidad se transmiten valores a través de las experiencias vividas, Canuto y Martínez (2016) escriben que con esto se busca perpetuar hechos dignos de ser recordados en la memoria común de las comunidades que pueden servir de referentes sobre cómo se debe actuar en ciertas circunstancias de la vida. Esta tradición oral la vi reflejada en los espacios de trabajo para la creación de la vestimenta pues permite a los diversos colectivos o familias recuperar relatos a través de pláticas diarias que fortalecen la comunicación de sus integrantes y crean un vínculo que recupera la historia del bordado. Desde los relatos de sus madres o abuelas, hasta cuando compran y venden en el mercado, van transmitiendo sus emociones empatizando o no con los demás, Santagada (2003) apunta que para viabilizar un sentimiento comunitario es preciso encontrar zonas de intersección entre expectativas, rencores o miedos. Una identidad reactiva a la comunidad que parece consentirlo todo.
El sentir comunitario involucra varias generaciones de mujeres en la actividad de bordar. En el caso de Marta, su mamá bordaba servilletas para tapar la masa o guardar las tortillas, también bordaba en piezas que después unía para hacer blusas. Esta actividad se hacía en casa de su abuela y su tía abuela, pues fortalecía el tejido familiar.

Marta aprendió esta técnica gracias a las mujeres mayores de su familia, heredando el gusto por trabajar en el bordado y transmitiéndolo después a sus hijas. Arely, una de las hijas de Marta aprendió por su madre y abuela a realizar la técnica de las flores, especialmente de pensamientos, que adornan los cajones de las blusas. Forma parte ahora de un equipo de trabajo que le permite intercambiar los trabajos realizados por cada compañera y conocer sus técnicas y al sentarse a trabajar conocer sus historias.

Arely tiene una hija de dieciocho años que ha aprendido a bordar y a dibujar porque de esta forma está más cercana y conectada con la historia de su comunidad. Participa en la delegación de baile de San Antonino y su interés es promover a la comunidad a través de la identidad, un proceso que debe pasar por la recuperación de las memorias de las mujeres de su familia que construyen recuerdos de cómo se fundó San Antonino, qué valores las representan, qué actividades han realizado y qué significa en lo individual y en lo colectivo pertenecer a esta comunidad.

El bordado "de San Antonino" se caracteriza por la creación de la flor inmortal el "hazme si puedes" o la flor que nunca muere, como la memoria. Cada flor en las prendas representa una historia de vida y memorias listas para compartirse. Las flores no solo se encuentran en los campos, sino en la vestimenta en que las mujeres plasman con sus manos, manos que cultivan la tierra y ahora cultivan a los jóvenes para que no olviden su origen. 


\section{Puntadas finales}

La investigación me permitió observar que la tarea de las mujeres que bordan no es solamente elaborar la prenda, sino que abarca un conjunto de intervenciones personales y comunitarias. Mediante un proceso de transmisión intergeneracional de conocimientos y la herencia de la práctica, buscan la forma de preservarla.

Es difícil que se aprenda esta próctica si no se está inmerso en una familia de bordadoras. Por ejemplo, en las comunidades cercanas a la capital oaxaqueña son las jóvenes quienes tienen el interés de aprender de la comunidad y participar en actividades culturales.

En los bailes, en la gastronomía y en el bordado buscan recuperar la historia de su pueblo y el origen de sus familias, si eres bordadora, artesana, alfarera, placera o panadera es un legado que la familia perpetua.

Por el contrario, las niñas que bordan son pocas, porque los padres aun perteneciendo a una familia de bordadores mandan a sus hijas a estudiar para obtener más conocimientos, acuden a las escuelas, practican deportes, realizan otras actividades y queda poco tiempo para aprender a bordar. Cuando llegan a ser jóvenes, nuevamente se interesan en sus memorias y vuelven a donde comenzó todo.

El bordado entrelaza y articula diversos conocimientos de sujetos y culturas involucrados en su producción. Narra una historia y busca la incorporación de los elementos cotidianos, de las tradiciones, relaciones interpersonales, educación y familia.

Con esta investigación descubrí una red de compartición de saberes que involucra bordadoras de distintas comunidades de la región de los Valles Centrales de Oaxaca para continuar un conocimiento heredado que forma parte de la construcción de sus historias.

La práctica del bordado comparte la música de viento que entona el jarabe del valle mientras sus mujeres bailan celebrando a la Virgen del Carmen. Engalana a quien porta la vestimenta orgullosa en las comidas, misas o tequios. Transmite la herencia de una cultura zapoteca contribuyendo a no perder de vista los orígenes de la comunidad. Expresa en el tiempo, las historias, la vida y hasta fechas importantes de mujeres que contribuyeron a la creación de cada prenda. El bordado reivindica la identidad, recupera la memoria y se vuelve soporte para la conservación y trasmisión de experiencias.

En la práctica de bordar se conservan costumbres y tradiciones que ofrecen la construcción de una identidad con el entorno para la formación de sujetos que responden al tequio en la comunidad que habitan. Permite la apropiación y reconstrucción de su propia formación a partir de la historia de vida.

En esta narración las mujeres resaltan su formación como bordadoras haciendo presentes la relación familiar produciendo un cambio ya que al hablar de sus primeras experiencias y logros en la práctica del bordado reconstruyen y reviven su historia familiar, compartiendo experiencias, emociones y logros.

Estas historias nos adentran a la dinámica de socialización del conocimiento que manifiesta el aprendizaje del bordado en donde el gusto, la participación y el interés hacen posible la consolidación de esta práctica (Carvente y Hernández, 2017).

La práctica del bordado atraviesa a la comunidad de San Antonino como actividad en la que sus mujeres tienen los elementos para recuperar la memoria y la 
historia del pueblo. Para los municipios cercanos pertenecientes a Ocotlán, el bordado de "San Antonino" une a las comunidades bajo una técnica ancestral que han aprendido intergeneracionalmente y que los une de igual forma con sus memorias familiares.

En la ciudad de Oaxaca, la práctica del bordado refleja un conocimiento de las mujeres que van a comercializar sus productos, pero en el proceso se incorpora la identidad de cada uno de los pueblos a los que pertenece la blusa, a las familias que las hicieron y a los relatos que se construyeron en los meses de su creación.

"El bordado nunca acaba" dice Marta a unas turistas que llegaron al colectivo, "con el tiempo nos transformamos y reinventamos, pero las mujeres sabemos que lo primero, siempre debe estar acompañando, nunca debe faltar el vestido o la blusa", es decir, el bordado de "San Antonino" es lo que nunca debe faltar, aunque se modernice la ropa, cambien las telas o los colores se difuminen.

Las adecuaciones que con el tiempo se dan no deben hacer a un lado la creación de lo que es primordial para las bordadoras que son el vestido y blusa del pueblo.

El bordado basado en las imágenes de sus recuerdos y expuesto con base en sus vivencias, sigue el patrón de lo comunitario, pero personalizándose en colores y formas, por eso es por lo que las blusas no son iguales, así también son las vivencias, se siguen reglas, pero vivimos nuestros propios caminos, así la mujer que sabe bordar guarda en sus manos los recuerdos, pero nunca se verán las mismas guías de flores.

\section{Referencias}

- Almeida Acosta, E. y Sánchez Díaz de Rivera, M. Comunidad. Interacción, conflicto y utopía. Puebla: Universidad Iberoamericana Puebla, Instituto Tecnológico y de Estudios Superiores de Occidente, Benemérita Universidad Autónoma de Puebla. 2014.

- Ameigeiras, A. R. El abordaje etnográfico en la investigación social. En I. Vasilachis, Estrategias de investigación cualitativa. Barcelona: Gedisa. 107-150. 2006.

- Bauman, Z. Comunidad. En busca de seguridad en un mundo hostil. Madrid: Siglo XXI de España Editores, S.A. 2003.

- Blanca, R. M. El bordado en lo cotidiano y en el arte contemporáneo: ¿práctica emergente o tradicional? En Revista Feminismos, 2(3). 2014.

- Blancarte, R. Las identidades religiosas de los mexicanos. En R. Blancarte, Culturas e Identidades. México: El Colegio de México. Vol. XVI 87-114. 2010.

- Canuto Castillo, F., \& Martínez de la Rosa, A. Altares y rezos para las ánimas. Literatura y tradición para recibir y despedir a los muertos. En A. Martínez de la Rosa, Identidades y Patrimonios. Encrucijadas entre lo material y lo intangible. Distribuciones Fontamara,121-142. S.A. 2016.

- Carvente Flores, E., \& Hernández Soriano, J. A. La formación de los tejedores lkoots, una representación en torno a sus creaciones.

Congreso Nacional de Investigación Educativa. San Luis Potosí. 2017.

- García Canclini, N. Culturas híbridas. Estrategias para entrar y salir de la modernidad. México: GRIJALBO. 1989.

- Gil Corredor, C. A. La estética textil como intersubjetividad de los pueblos originarios: caso de las tejedoras mayas. Revista San Gregorio 1(11), 58-59. 2016

- Giménez, G. Cultura, identidad y memoria Frontera Norte, 21(41), 7-32. 2009.

- Giménez, G. Estudios sobre la cultura y las identidades sociales. Guadalajara: CONACULTA/ITESO.2016.

- Gutiérrez , R., \& Salazar Lohman, H. Reproducción comunitaria de la vida. Pensando la trans-formación social en el presente. El Apantle. Revista de estudios comunitarios(1), 17-49. 2015.

- Martínez Luna, J. Conocimiento y Comunalidad. Bajo el volcán.(23), 99-1 12. 2015-2016.

- Santagada, M. La construcción reactiva de las identitades. Teologías, cotidiandad y riesgo. (U. N Centro, Ed.) Coloquio Identidades Revis (it) adas: Artes Visuales e Identidades en Iberoamérica 1-10. 2003. 
(1) El Estado de Oaxaca se divide en regiones: la Costa colinda con el océano pacífico y está situada al sur del Estado. El Papaloapan colinda con los Estados de Puebla y Veracruz y se sitúa al norte del Estado. La Sierra Norte forma parte de la Sierra Madre del Sur y es una gran área de biodiversidad en el Estado, se sitúa en el noroeste del Estado. La Sierra Sur es la región montañosa ubicada en el suroeste del Estado. El Istmo es la región más grande del Estado de Oaxaca colinda con el océano pacífico y los Estados de Veracruz y Chiapas. La Cañada es la región más pequeña del Estado ubicada al noroeste. La Mixteca ubicada al norte del Estado y los Valles Centrales compuestos por los valles de Etla, Ocotlán y Zimatlán.

(2) Se crean utensilios de cocina o figuras hechas de barro rojo, canastas y bolsas de carrizo para llevar objetos dentro, y la blusa y vestido bordado y deshilado en los diversos colores de las flores de sus campos de cultivo.

(3) La ruta involucra 6 municipios: Santa María Atzompa, San Bartolo Coyotepec, San Martín Tilcajete, Santo Tomás Jalieza, San Antonino Castillo Velasco y Ocotlán de Morelos. Hacen alebrijes (figuras talladas en madera, de animales reales o míticos, algunas veces mezclados entre sí, pintadas a mano con colores brillantes); tejidos en telar; mezcal (destilado de maguey); barro verde, negro y rojo; bordados y deshilados; por mencionar algunas.

(4) La etnografía es un proceso metodológico que permite replantear la construcción del conocimiento en la práctica social a la vez que se requiere un compromiso del investigador en el trabajo de campo y con los actores sociales. (Ameigeiras, 2006). Los investigadores deben interactuar, observar y participar en las situaciones de espacio-temporalidad determinadas.

(5) La observación participante "supone un tipo de propuesta en la cual intervienen distintas técnicas y métodos, vinculados tanto con formas de observación, modalidades de interacción como tipos de entrevistas" (Ameigeiras, 124, 2006).

(6) La distancia entre Oaxaca y San Antonino es de aproximadamente $33 \mathrm{~km}, 45$ minutos según las condiciones del tráfico.

(7) Durante el mes de julio se lleva a cabo una fiesta representativa en la ciudad de Oaxaca y se extiende al Estado en general en donde las regiones participan en un intercambio de bailes, gastronomía, artesanías y eventos culturales y artísticos abiertos al público. Las fiestas de julio comienzan con la celebración a la Virgen del Carmen el día 16 de julio.

(8) El trabajo de campo en Oaxaca y San Antonino duró aproximadamente seis meses. Entre junio y agosto de 2017 realicé visitas continuas y entre octubre y noviembre las entrevistas.

(9) Cada una de las mujeres pertenecen a municipios de Valles Centrales. La práctica de bordado es característica de los municipios cercanos a la capital. Las mujeres usan diversas técnicas en su realización, sin embargo, sigue nombrándose como bordado "de San Antonino" por el uso de las guías de flores. Marta pertenece a San Antonino y se ubica aproximadamente a 33 $\mathrm{km}$. Beatriz vive en el municipio de San Pedro Mártir a $40 \mathrm{~km}$. Juana es de San José del Progreso ubicado a $46 \mathrm{~km}$, distancia a partir de la ciudad de Oaxaca, lugar en donde radica Mari.

(10) Pinotepa Nacional se ubica en la región de la Costa de Oaxaca aproximadamente a $400 \mathrm{~km}$ de distancia de la capital oaxaqueña.

(11) San Pedro Mártir es un municipio perteneciente al distrito de Ocotlán en los Valles Centrales de Oaxaca, en la comunidad hombres y mujeres por igual se dedican a bordar y deshilar, particularmente han aprendido la técnica del deshilado.

(12) El bordado "de San Antonino" se borda con hilos de seda sobre tela popelina de colores. Se caracteriza por la creación de la flor inmortal una flor que nace y que muere sin perder sus pétalos ni su color. Esta técnica consiste en hacer guías de flores de cuatro pétalos y remarcadas por varías tonalidades, seguidas de flores características de la región: fusias, angelinas, pensamientos, pajarillos y una guía de hojas para unirlas.

(13) San José del Progreso es un municipio perteneciente al distrito de Ocotlán en los Valles Centrales de Oaxaca.

(14) Este colectivo se compone de 19 personas que trabajan con diferentes horarios y actividades y de 60 personas externas que realizan el trabajo desde su casa. La división del trabajo se hace por equipos 1) Bordado, 2) Deshilado, 3) Tejido, 4) Dibujo y 5) Armado. Estos equipos se dedican a la creación de la blusa y vestido tardando entre 1 y 3 meses en su elaboración. Varía el tiempo según su dificultad, el trabajo a realizar, la compañera o compañero que lo haga y la demanda.

(15) San Mateo del Mar se ubica en la región del Istmo aproximadamente a $300 \mathrm{~km}$ de la capital oaxaqueña. 
(16) En Oaxaca una mayordomía es la gestión de recursos para celebraciones religiosas. Está a cargo de 1 o 2 personas que realizan actividades para la comunidad. La comida, la decoración y la música para la celebración, son ejemplos de algunas de ellas.

(17) En los días de plaza se ofrecen los productos cosechados del campo, se abre el mercado a la comida preparada en casa, dulces, pan de horno, artesanías, ropa, trastes y otros utensilios para el hogar. Se realiza todos los domingos en la comunidad de San Antonino Castillo Velasco.

(18) El baratillo es un mercado en el que se exponen a la venta animales como: toros, vacas, chivos, gallos, caballos, cabras, conejos, becerros, gallinas, entre otros. Se realiza todos los viernes en la comunidad de San Antonino Castillo Velasco.

(19) El deshilado en las prendas permite realizar varias figuras en la blusa o vestido, ejemplos de ello son los muñecos que son figuras humanas diminutas, los zancudos que forman una cruz al centro y el nacional que permite observar una guía de flores.

(20) El tequio es una forma de trabajo que las personas realizan para el bienestar común, sin remuneración económica y que opera bajo la pauta de reciprocidad. (Martínez, 2016).

Para citar este artículo:

Castañeda - de la Cueva, E. (2018). LA PRÁCTICA CULTURAL DEL BORDADO "DE SAN ANTONINO" EN OAXACA - MÉXICO. Revista Luciérnaga / Comunicación. Año 10, № 20. Págs. 27 - 44

DOI: 10.33571/revistaluciernaga.v10n20a2

OJS. http://revistas.elpoli.edu.co/index.php/luc/issue/archive

Link. https://www.politecnicojic.edu.co/index.php/revista-luciernaga 